www.jmscr.igmpublication.org

Impact Factor 5.84

Index Copernicus Value: 71.58

ISSN (e)-2347-176x ISSN (p) 2455-0450

crossref DOI: _https://dx.doi.org/10.18535/jmscr/v6i1.136

Journal Of Medical Science And Clinical Research

\title{
A Comparative Study of Dexmedetomidine versus Magnesium Sulphate as an Adjuvant to Ropivacaine in Bier's Block in Upper Limb Surgery
}

\author{
Authors \\ Gill Rabia, Guliani Gurpreet
}

Deptt of Anesthesiology and Intensive care, Government Medical College \& Hospital, Patiala

\begin{abstract}
This prospective randomised double-blinded study was designed to compare the effects of adding dexmedetomidine and magnesium sulphate to ropivacaine during bier's block. Fifty ASA I or II patients scheduled for upper limb surgery under bier's block were recruited. Bier's block was achieved using ropivacaine in to which either $10 \mathrm{ml}$ of $15 \%$ magnesium sulphate or $1 \mu \mathrm{g} / \mathrm{kg}$ dexmedetomidine was added. There was no significant difference between the two groups regarding the onset or recovery of motor blockade. However, the onset of sensory block was significantly shortened in the dexmedetomidine group $(p<0.01)$.Also the sensory block recovery time was prolonged in the dexmedetomidine group, which was significant. $(p<0.01)$. VAS score for tourniquet pain was lower in the dexmedetomidine group. $(p<0.001)$. Perioperatively, there was a significant reduction in the number of patients requiring rescue analgesia and its consumed amount in the dexmedetomidine group compared to magnesium sulphate group. The quality of anesthesia was significantly better in the dexmedetomidine group compared to magnesium sulphate group. Patients in the dexmedetomidine group were more sedated briefly post-operatively. This study revealed that adding dexmedetomidine to ropivacaine during bier's block as an adjuvant is better than magnesium sulphate.
\end{abstract}

\section{Introduction}

Intravenous regional anaesthesia (IVRA) is one of the safest and most consistent modes of regional anaesthesia for short procedures on upper extremity. It is a technically simple and reliable technique, with success rates between $94 \%$ and $98 \%$.

Bier's block was first described in 1908 by August KG Bier for the anaesthesia of the hand and forearm and the earliest agent injected into the vascular space was procaine. ${ }^{(1)}$ After initial enthusiasm the technique fell into obscurity for more than 50 years. The technique regained popularity in the 1960's when Holmes used lidocaine. $^{(2)}$
Since its reintroduction, Intravenous regional anesthesia is one of the commonly used regional anaesthesia technique in everyday anaesthesia practice throughout the world with high degree of safety, efficacy, efficiency and satisfaction and it remains popular despite the introduction of nerve blocks because it is simple to administer, costeffective, reliable and applicable to all age groups. It is well suited for brief surgical procedures $(<90$ min) such as wrist, hand, forearm and those involving the leg below the knee including open procedures or closed reductions. The technique is employed as an alternative to general anaesthesia and is commonly used for procedures involving the upper limb and lower limb. ${ }^{(3)}$ 
The onset of surgical anaesthesia is quite rapid and after the tourniquet is released, normal sensation and motor power returns rapidly. Inspite of this, it has been limited by tourniquet pain and lack of ability to offer postoperative analgesia. Several LA adjuvants have been attempted with variable degrees of success but their use was limited by side effects, e.g. Mivacurium, clonidine, ketorolac, tenoxicam, ketamine, sufentanil, tramadol, methylprednisolone, magnesium or limited efficacy, e.g., opioids and acetylsalicylate. $^{(4)}$

For almost over a decade, the importance of magnesium in anaesthetic practice has been highlighted. Parenteral magnesium has been used for many years on an empirical basis as an antidysrhytmic treatment for eclampsia and for intraoperative and postoperative analgesia. ${ }^{(5)}$ It has been constantly suggested and proved that magnesium has the potential to treat and prevent pain by acting as an antagonist of N-Methyl-DAspartate (NMDA) receptors. ${ }^{(6)}$ Magnesium was used for the treatment of chronic limb pain in IVRA and it was demonstrated that the addition of magnesium to lidocaine improves the quality of the block, extends the analgesia, and reduces the overall failure rate. ${ }^{(7)}$ Studies have reported that magnesium has an endothelium derived nitric oxide-induced vasodilatory effect. Nitric oxide causes an activation of guanyl cyclase and an increase in cyclic guanine monophosphate, which mediates the relaxation of vascular smooth muscles. ${ }^{\left({ }^{8}\right)}$ With IVRA, the pneumatic tourniquet causes ischaemia, which distorts nerve penetration by oxidative stress and affects the blood nerve barrier. Nitric oxide donors have also been shown to protect vascular endothelium from ischaemia / reperfusion-mediated endothelial dysfunction. ${ }^{(9)}$

In recent years, $\alpha-2$ adrenergic receptor agonists have been focus of interest for their sedative, anxiolytic, perioperative sympatholytic and cardiovascular stabilizing effects in addition to their general anesthetic sparing effect and their ability to prolong local anesthesia induced analgesia when used in regional blocks. ${ }^{(10)}$
Dexmedetomidine, potent $\alpha_{2}$ adrenoreceptor agonist is approximately 8 times more selective towards $\alpha_{2}$-receptor than clonidine. It decreases anaesthetic requirements by upto $90 \%$ and induces analgesia in patients. It inhibits substance $P$ release in the nociceptive pathway. In addition, $\alpha$ 2 adrenergic receptors located at nerve endings may have a role in the analgesic effect of the drug by preventing norepinephrine release. ${ }^{(11)}$ Dexmedotimidine-ropivacaine mixture was used in our sttudy and was shown to improve the quality of anaesthesia, tourniquet pain and reduce perioperative analgesic requirement.

This study was done to compare the quality of anaesthesia, safety and efficacy of Dexmedetomidine and Magnesium sulphate when injected as an adjuvant analgesics to Ropivacaine in Bier's block in upper limb surgery.

\section{Aims and Objectives}

To compare the quality of anaesthesia, safety and efficacy of Dexmedetomidine and Magnesium sulphate when injected as an adjuvant analgesics to Ropivacaine in Bier's block in upper limb surgery in terms of:

- Onset of sensory block and recovery time

- Onset of motor block and recovery time

- Analgesic efficiency (tourniquet pain)

- Intraoperative and postoperative haemodynamics

- Intraoperative and post operative analgesic requirements

- Sedation score

- Quality of anaesthesia

\section{Materials and Methods}

Fifty patients of age group 18-60 years, ASA grade I or II, belonging to either sex, scheduled to undergo upper limb surgery under bier's block were randomly allocated to 2 groups of 25 patients each:

Group I (Mg: $\mathrm{n}=25)$

Patients received IVRA with Ropivacaine plus Magnesium sulphate, $40 \mathrm{ml}$ of Ropivacaine $0.2 \%$ 
plus $10 \mathrm{ml}$ of $15 \%$ magnesium sulphate $(12.4 \mathrm{~m}$ mole) to make a total volume of $50 \mathrm{ml}$.

Group II (Dex: $\mathrm{n}=25$ )

Patients received IVRA with Ropivacaine plus Dexmedetomidine, $40 \mathrm{ml}$ of Ropivacine $0.2 \%$ plus $1 \mu \mathrm{g} / \mathrm{kg}$ dexmedetomidine diluted with normal saline to make $50 \mathrm{ml}$.

Onset of sensory and motor block, Intraoperative haemodynamic changes, analgesic efficiency, intraoperative and postoperative analgesic requirements, sedation scores, sensory and motor recovery time, postoperative haemodynamic changes and the quality of anaesthesia were recorded. Post operative follow up was done till patient stays in recovery room. Data collected was statistically analysed using chi square, $t$ test.

\section{Observations and Results}
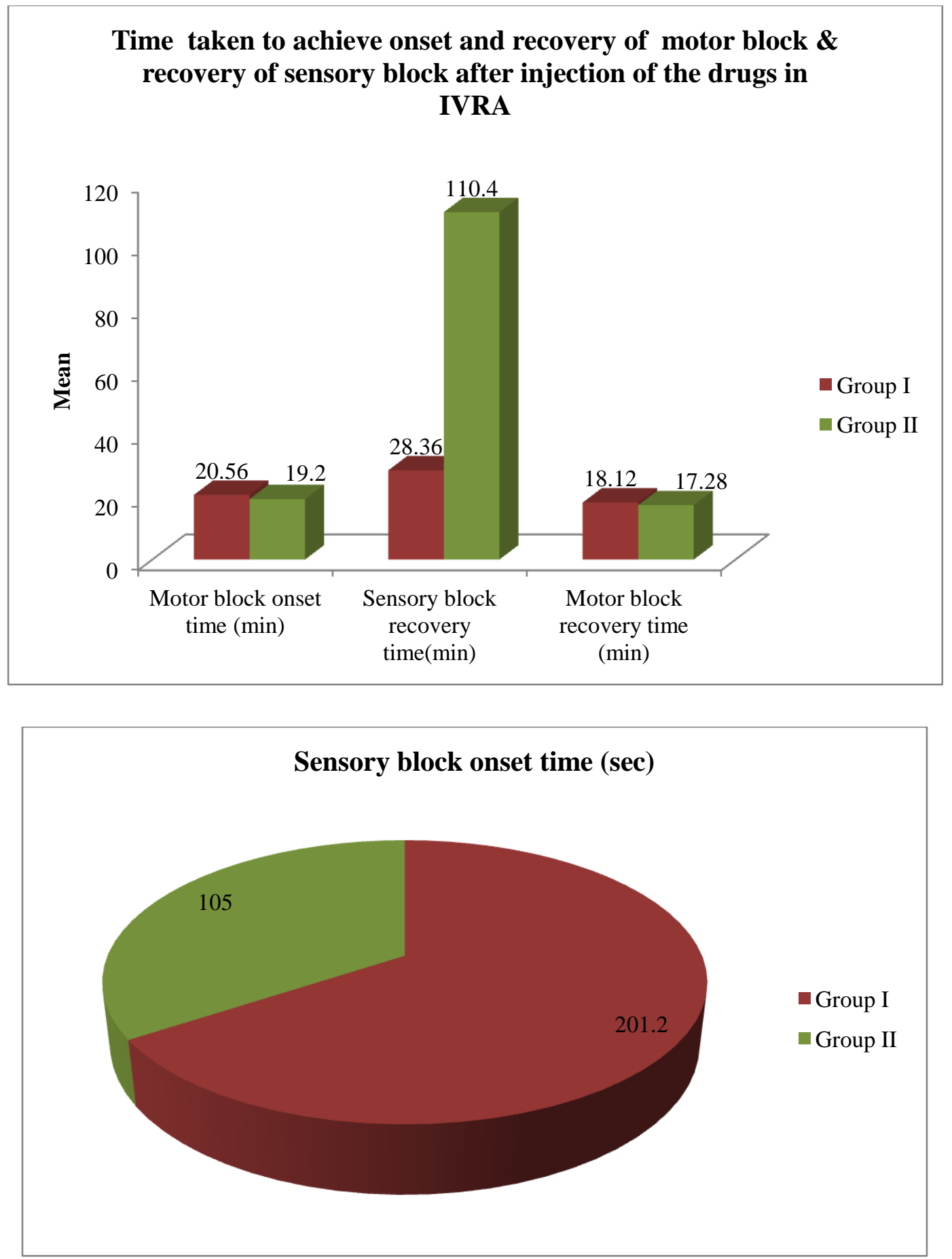

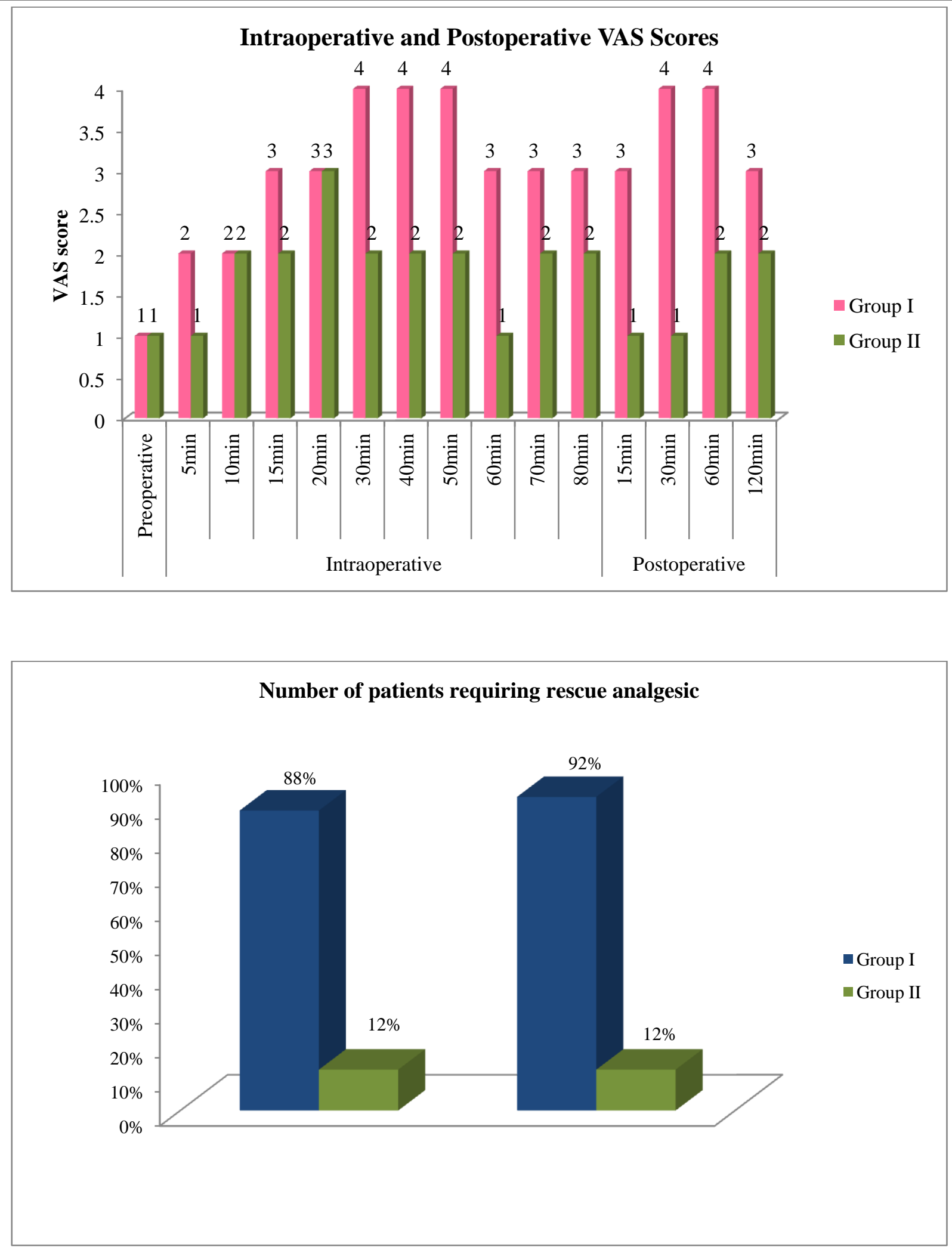


\section{Perioperative analgesic consumption}
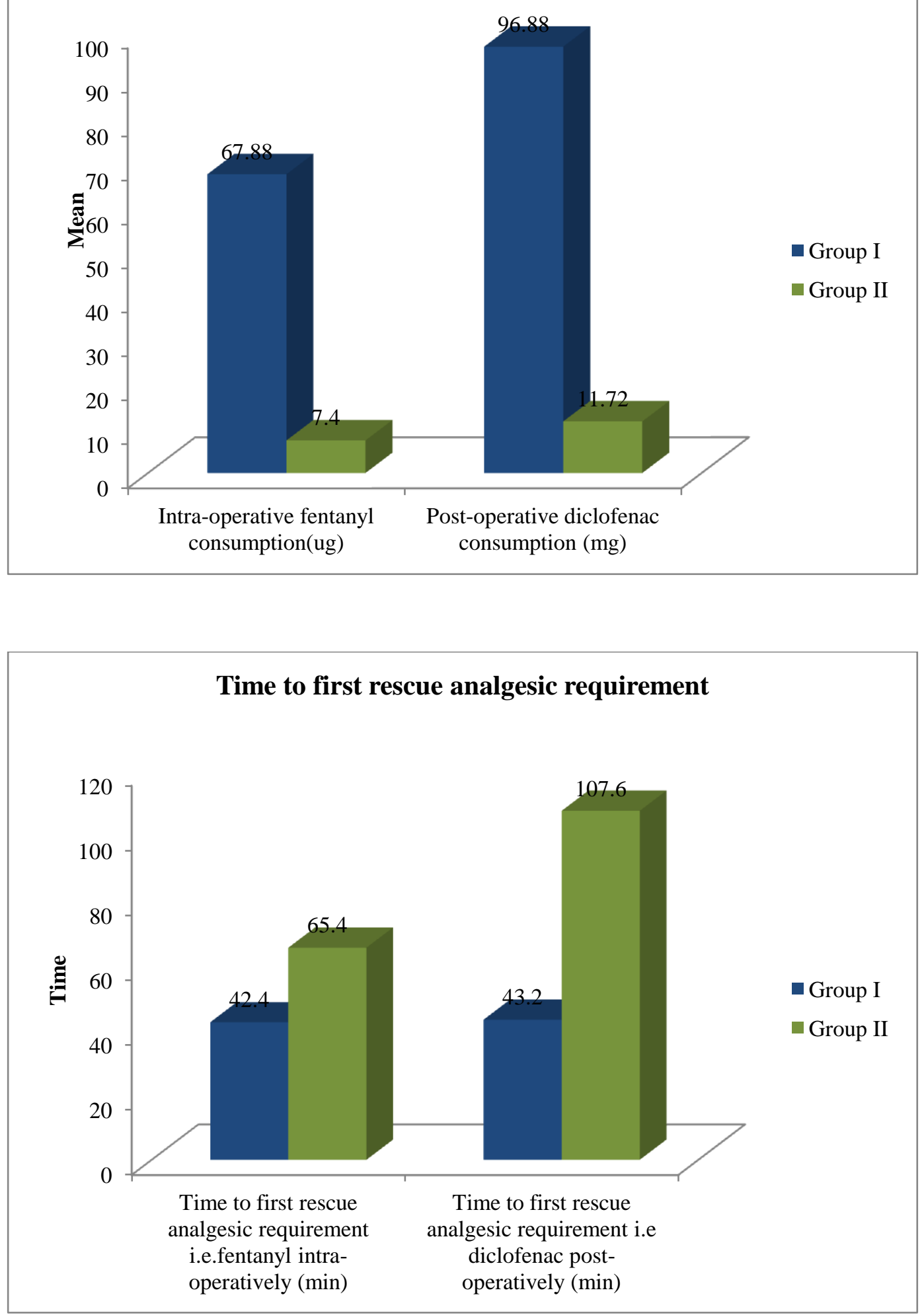

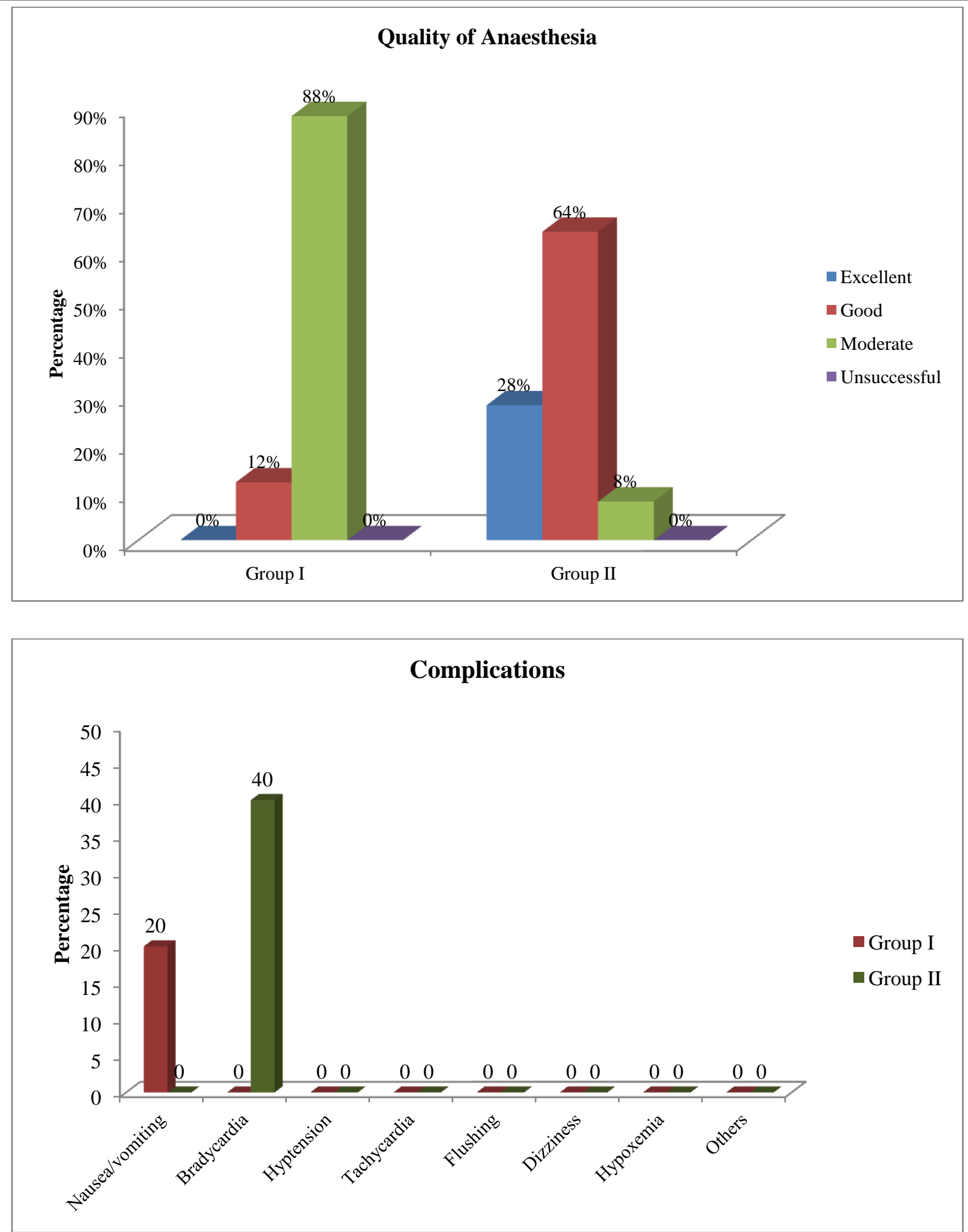

\section{Conclusion}

After the analysis of results and observations of the present study, following conclusions can be drawn:

1) Dexmedetomidine in the dose of $1 \mathrm{ug} / \mathrm{kg}$ when used as an adjuvant to ropivacaine $0.2 \%$ for IVRA hastens the onset of sensory block and provides significant post-deflation analgesia which extended beyond the postoperative period.

2) Dexmedetomidine when used as an adjuvant to ropivacaine reduces the intraoperative and postoperative analgesic requirements.

3) Dexmedetomidine when used along with ropivacaine had no significant 
intraoperative and postoperative side effects except for post deflation bradycardia which can be treated with i.v inj atropine.

4) The use of dexmedetomidine as an adjuvant to ropivacaine provides excellent to very good intraoperative surgical conditions.

5) The post-deflation increased sedation scores are seen with dexmedetomidine not requiring any supplemental oxygen.

6) It is safe to use dexmedetomidine for IVRA as an adjuvant to ropivacaine.

Thus it can be concluded and recommended that dexmedetomidine can be used as an adjuvant with ropivacaine in IVRA for reducing the analgesic requirements, to hasten the onset of sensory block and to improve the quality of anaesthesia.

\section{Bibliography}

1. Bannister M: Biers Block. Anaesthesia 1997;52:713.

2. Holmes CMCK. Intravenous regional neural blockade. In: cousins MJ, Bridenbaugh PO (Eds.) Neural Blockade in clinical Anaesthesia and Mangement of pain, $3^{\text {rd }}$ ed. Philadelphia: LippincottRaven, 1998:365-410

3. Van Zundert Andre M.D; Ph.D, FRCA et al. Regional Anaesthesia and Pain Medicine Sept/Oct 2008-Vol33-Issue 5P483-489.

4. Choyce A and P. Pgeng. A systemic review of adjuncts for IVRA for surgical procedures. Can J Anaesth 2002;49:32-45.

5. Koinig H, Wallner $\mathrm{T}$, Marhofer $\mathrm{P}$, et al. Magnesium sulfate reduces intra and postoperative analgesic requirements. Anaesth Analg 1998; 87:206-10.

6. Woolf CJ, Thompson SWN. The induction and maintenance of central sensitization is dependent on N-methyl-D-aspartic acid receptor activation: implication for the treatment of post-injury pain and hypersensitivity states. Pain 1991;44:2939.

7. Tramer RM, Glynn CJ. Magnesium Bier's Block for treatment of chronic limb pain: a randomized, double blind, cross-over study. Pain 2002;99:235-41.

8. Mallet RT, Sun J, Fan WL, et al. Magnesium activated adenosine formation in intact perfused heart: predominance of ecto 5, -nucleotedase during hypermagesemia. Biochim Biophys Acta 1996;1290:165-76.

9. Katzung BG, Chatterjee k. Vasodilators and treatment of angina pectoris. In: Katzung BG, ed. Basic and clinical pharmacology. Stamford, CT: Appleton and Lange, 1998;179-304.

10. Murphy, DB, C.JL MC Cartney and VWS Chan, Novel analgesic adjuncts for brachial plexus block: Asytemic review. Anesth. Analg.,2000;90:1122-1128.

11. Kamibayashi, T. and M. Maze. Clinical uses of alpha-2-adrenergic agonists. Anaesthesiology 2000;93:1345-49. 